\title{
CYTOGENETICAL STUDIES ON THE GENUS ORYZA
}

\section{ALIEN ADDITION LINES OF O. SATIVA WITH SINGLE CHROMOSOMES OF O. OFFICINALIS}

\author{
YOUNG-BOUM SHIN ${ }^{1)}$ AND TAIRA KATAYAMA ${ }^{2)}$ \\ Plant Breeding Laboratory, Faculty of Agriculture, \\ Kyushu University, Fukuoka 812
}

Received July 13, 1978

\begin{abstract}
From crosses between allotriploid plants with genomes AAC and diploid $O$. sativa plants (AA), twelve types of alien addition lines with single C-genome chromosome were distinguished on the basis of morphological characteristics of the addition type plants. Of the twelve chromosomes of $O$. officinalis (W0065), six appeared to be homoeologous with those of $O$. sativa in varying degrees. The occurrence of many univalents in the PMCs of two alien addition lines, G and J, suggests that two chromosomes of $O$. officinalis (W0065) have genes which disturb the pairing of homologous sativa chromosomes.
\end{abstract}

\section{INTRODUCTION}

Since Sears (1956) transferred the leaf-rust resistance of Aegilops umbellulata to common wheat, the transfer of useful genes from wild to cultivated plants has been attempted by many workers. When the chromosomes of wild and cultivated species fail to pair normally, establishing alien chromosome addition lines has been a way of approach. There are some reports on the alien addition lines of common wheat with Secale cereale chromosomes (Riley and Chapman 1958; Evans and Jenkins 1960; Mukade et al. 1970), those of tetraploid wheat with Aegilops squarrosa (Alston 1970) and with Agropyron elongatum chromosomes (Mochizuki 1962) and those of Avena sativa with A. hirtula chromosomes (Thomas 1968).

To explore the possibility of transfer of disease and insect resistance genes from wild Oryza species to $O$. sativa, the authors have tried to isolate alien addition lines from crosses between allotriploid plants with different genomic constitutions $\mathrm{AAB}$ and AAC, as reported by Shin et al. 1978) and O. sativa (AA). The wild species used for this experiment were O. officinalis Wall. (CC), O. collina (Trimen) Sharma et Shastry (CC, Ceylonese officinalis), an intermediate form (CC, between O. punctata and $O$. eichingeri) and diploid $O$. punctata Kotschy et Steus. (BB).

1) Present address: Department of Agriculture, Gangweon National University, Chuncheon, Korea 200.

2) Present address: 1-8-3, Miwadai, Higashi-ku, Fukuoka 811-02. 
From the cross of $\mathrm{AAC} \times \mathrm{AA}$, the authors have succeeded in isolation of twelve different types of $2 n=25\left(\mathrm{AA}+\mathrm{C}_{X}\right.$ ) plants. Presumably, each of them has a different chromosome of $O$. officinalis. Cytological and morphological investigations of those plants are reported in this paper.

\section{MATERIALS AND METHODS}

The initial cross was made between a tetraploid strain of an $O$. sativa cultivar (Sekitori, from National Institute of Agricultural Sciences, AA) and a diploid strain of O. officinalis (W0065, from National Institute of Genetics, CC) as reported by Shin et al. (1978). The allotriploid $F_{1}$ plants obtained from this cross were backcrossed with Sekitori (1974-76). Plants having $2 n=25$ chromosome were obtained from the backcrosses as well as in the selfed progenies of $2 n=26$ or $27 \mathrm{~B}_{1}$ plants.

Their seeds were sterilized and sown on the artificial culture medium in test tubes. The cultured seedlings were transplanted into pots. In order to promote floral initiation, the plants were subjected to short-day conditions (about $9 \mathrm{~h}$ ).

The root tips were pretreated with $0.002 \mathrm{M}$ 8-oxyquinoline at $18-20^{\circ} \mathrm{C}$ for $2-3 \mathrm{~h}$. After fixing with acetic-alcohol (1:3), the root-tip and pollen-mother-cells (PMCs) were stained with acetocarmine.

The electrophoretic analysis using mature leaf blades was used for isolating alien chromosome addition lines having an acid phosphatase zymogram as of $O$. officinalis $(\mathrm{W}$ 0065). The procedure of the electrophoresis was described by Katayama and Chern (1973).

\section{RESULTS}

Results of crossing and selfing: From the backcrosses, 1,218 seeds were obtained during three years, and they were sown under a sterile condition. From 688 germinated seeds, 405 plants grew up to the adult stage. Besides this, 96 plants were obtained from the selfing of $2 n=26$ and $27 \mathrm{~B}_{1}$ plants. Their somatic chromosome numbers

Table 1. Somatic chromosome numbers of plants from AAC $\times$ AA crosses and in the selfed progeny of $2 n=26$ and $2 n=27$ plants

\begin{tabular}{|c|c|c|c|c|c|c|c|c|c|c|c|c|c|}
\hline & \multicolumn{11}{|c|}{ Chromosome number } & \multirow[b]{2}{*}{54} & \multirow{2}{*}{ Tota } \\
\hline & 24 & 25 & 26 & 27 & 28 & 29 & 30 & 31 & 32 & 33 & 36 & & \\
\hline \multicolumn{14}{|c|}{ Backcross } \\
\hline 1974 & 1 & & & 2 & & & 1 & & 1 & & & & 5 \\
\hline 1975 & 10 & 10 & 5 & 8 & 4 & & 3 & & 2 & & 1 & & 43 \\
\hline 1976 & 40 & 23 & 28 & 50 & 77 & 69 & 46 & 12 & 8 & 3 & & 1 & 357 \\
\hline \multicolumn{14}{|l|}{ Selfing } \\
\hline $2 n=26$ & 16 & 32 & 8 & & & & & & & & & & 56 \\
\hline $2 n=27$ & 7 & 17 & 16 & & & & & & & & & & 40 \\
\hline Total & 74 & 82 & 57 & 60 & 81 & 69 & 50 & 12 & 11 & 3 & 1 & 1 & 501 \\
\hline
\end{tabular}


varied from $2 n=24$ to 54 (Table 1). The numbers of plants with $2 n=25$ (alien chromosome addition lines), 26 and 27 chromosomes were 82,57 and 60 , respectively.

The origin and number of each type of alien chromosome addition lines with $2 n=$ 25 chromosomes, thus obtained, are presented in Table 2.

Table 2. Numbers of 12 types of alien chromosome addition lines obtained and their sources

\begin{tabular}{|c|c|c|c|c|c|c|c|c|c|c|c|c|c|}
\hline \multirow[b]{2}{*}{ Origin } & \multicolumn{12}{|c|}{ Plant type } & \multirow[b]{2}{*}{ Total } \\
\hline & $\mathrm{A}$ & $\mathrm{B}$ & $\mathrm{C}$ & $\bar{D}$ & $E^{-}$ & $\mathrm{F}$ & $\mathrm{G}$ & $\mathrm{H}$ & $\mathrm{I}$ & $\mathrm{J}$ & $\bar{K}$ & $\mathrm{~L}$ & \\
\hline \multicolumn{14}{|l|}{ Allotriploid (AAC) } \\
\hline$x$ & 20 & 3 & 2 & 1 & 1 & 1 & 1 & 1 & & 1 & 2 & & 33 \\
\hline \multicolumn{14}{|l|}{ Sekitori (AA) } \\
\hline \multicolumn{14}{|l|}{ Selfing } \\
\hline $\mathrm{AD} \quad 1(2 n=27)$ & & & & 5 & & & & & 1 & & & 8 & 14 \\
\hline AD $11(2 n=27)$ & 1 & & & & & & & & 1 & & & 1 & 3 \\
\hline $\mathrm{AD} 24(2 n=26)$ & 20 & 12 & & & & & & & & & & & 32 \\
\hline Total & 41 & 15 & 2 & 6 & 1 & 1 & 1 & 1 & 2 & 1 & 2 & 9 & 82 \\
\hline
\end{tabular}

These may be compared with the alien addition lines having $O$. australiensis chromosomes reported by Wu et al. (1967).

Morphological characteristics: Eighty-two alien chromosome addition lines in total were classified into the following twelve types on the basis of their vigor, growth habit, stature, rolling of leaves, panicle and spikelet shapes, awnedness, seed setting and other characteristics (Table 3, Fig. 1).

Type A: Long grain, thick stem, horizontal stretch of flag-leaf, slight reduction in height, and high fertility.

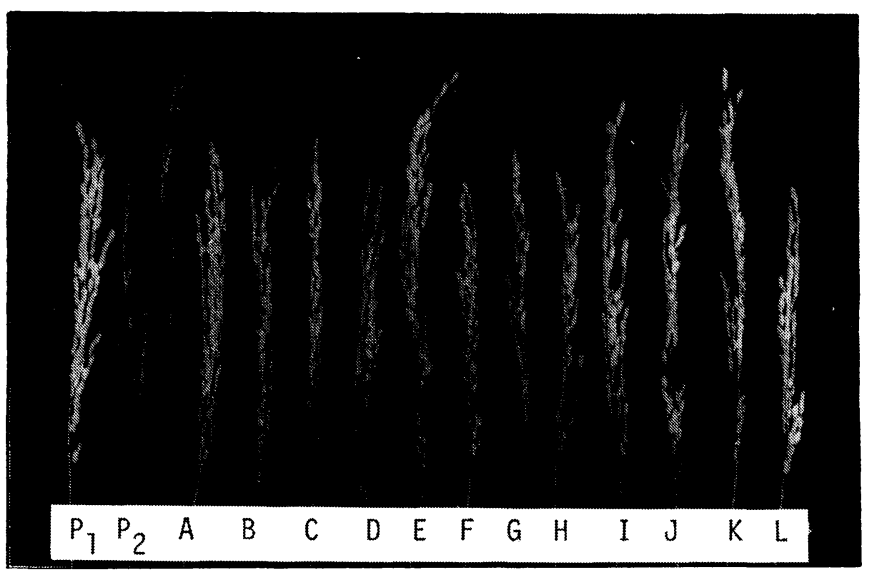

Fig. 1. Panicles of alien chromosome addition lines and their parents. $\mathrm{P}_{1}$ : Sekitori $(2 \mathrm{x}) . \quad \mathrm{P}_{2}$ : O. officinalis (W0065, 2x). A-L: Twelve alien chromosome addition lines (cf. Table 3 ). 


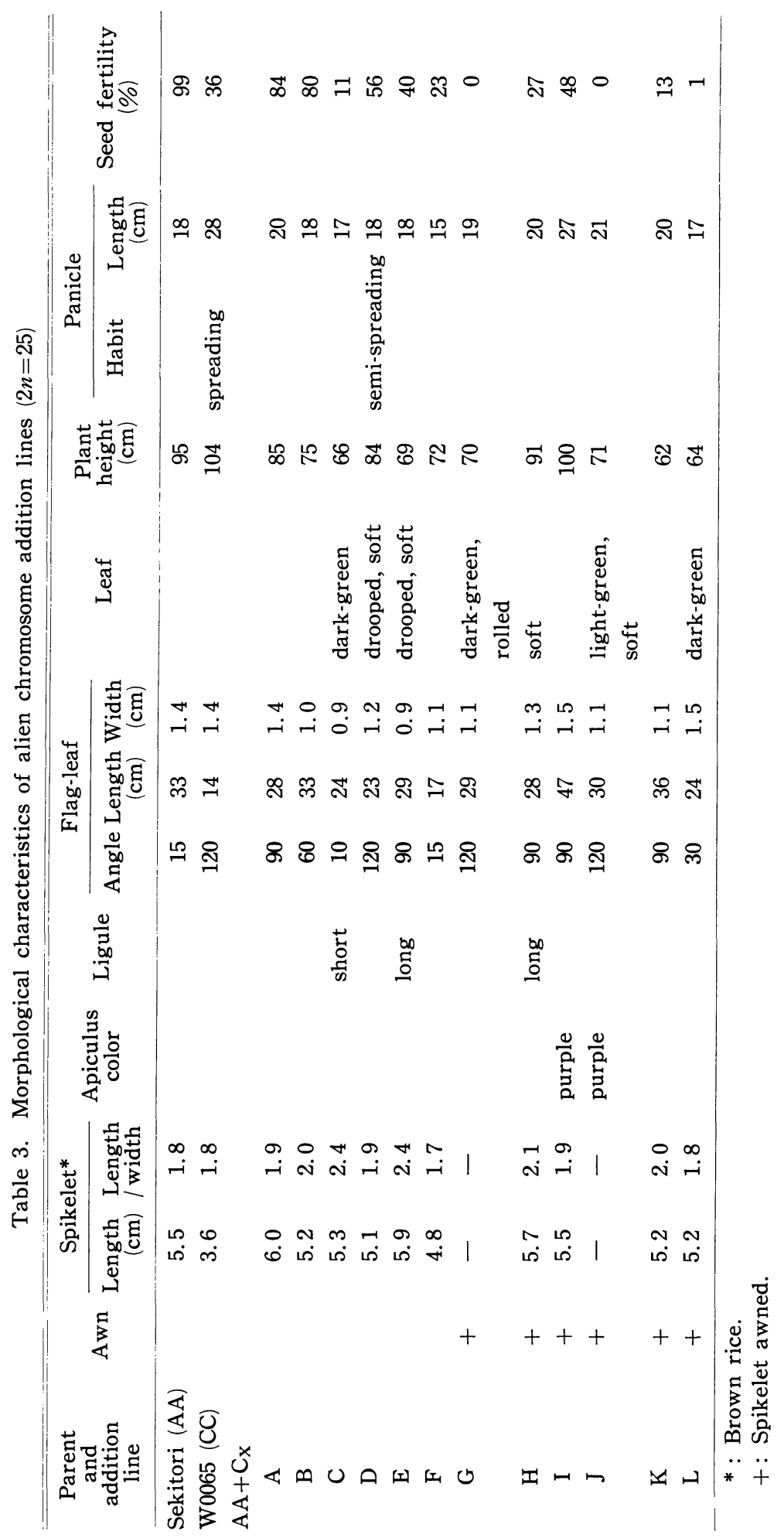


Type B: Slight reduction in height, thin uppermost internode, and high fertility.

Type C: Large grain, elect panicle, short ligule, narrow angle of flag-leaf, narrow and dark green leaves, reduced height, and low fertility.

Type D: Hanging of flag leaf, drooped and soft leaves, thin stem, semi-spreading panicle, and semi-sterility.

Type E: Long grain, long ligule, horizontal stretch of flag-leaf, narrow, drooped and soft leaves, thin stem, and semi-sterility.

Type F: Small grain, short and narrow angle of flag-leaves, short and compact panicles, and low fertility.

Type G: Hanging, drooped, slightly rolled and dark green leaves, awnedness, and sterility.

Type H: Long ligule, awnedness, horizontal stretch of flag-leaf, soft leaf, low fertility, and the same acid phosphatase zymogram as that of O. officinalis (W0065) (Shin 1977).

Type I: Purple apiculus, awnedness, horizontal stretch of flag-leaf, tall height,

Table 4. Chromosome configurations at MI in the PMCs of alien monosomic addition lines

\begin{tabular}{|c|c|c|c|c|c|c|c|c|c|c|c|c|}
\hline \multirow{2}{*}{$\begin{array}{l}\text { Chromosome } \\
\text { configuration }\end{array}$} & \multicolumn{12}{|c|}{ Plant type } \\
\hline & $\mathrm{A}$ & $\mathrm{B}$ & $\mathrm{C}$ & $\mathrm{D}$ & $\mathrm{E}$ & $\mathrm{F}$ & G & $\mathrm{H}$ & I & $\mathrm{J}$ & $\mathrm{K}$ & $\mathrm{L}$ \\
\hline $1 I I I+11 I I$ & 38 & 19 & & 8 & 1 & 1 & & 1 & 7 & 6 & & 3 \\
\hline $1 \mathrm{III}+10 \mathrm{II}+2 \mathrm{I}$ & & & & & & & & & & 2 & & \\
\hline $1 \mathrm{III}+9 \mathrm{II}+4 \mathrm{I}$ & & & & & & & & & & 2 & & \\
\hline $1 \mathrm{III}+8 \mathrm{II}+6 \mathrm{I}$ & & & & & & & & & & 1 & & \\
\hline $1 \mathrm{III}+7 \mathrm{II}+8 \mathrm{I}$ & & & & & & & & & & 1 & & \\
\hline $1 \mathrm{III}+6 \mathrm{II}+10 \mathrm{I}$ & & & & & & & & & & 2 & & \\
\hline $1 \mathrm{III}+5 \mathrm{II}+12 \mathrm{I}$ & & & & & & & 1 & & & 3 & & \\
\hline $1 \mathrm{III}+4 \mathrm{II}+14 \mathrm{I}$ & & & & & & & & & & 1 & & \\
\hline $1 \mathrm{III}+3 \mathrm{II}+16 \mathrm{I}$ & & & & & & & & & & 3 & & \\
\hline $1 \mathrm{III}+2 \mathrm{II}+18 \mathrm{I}$ & & & & & & & & & & 1 & & \\
\hline $12 \mathrm{II}+1 \mathrm{I}$ & 19 & 19 & 111 & 67 & 46 & 39 & 1 & 72 & 56 & 11 & 85 & 52 \\
\hline $11 I I+3 I$ & & 2 & 4 & 3 & 1 & & 1 & 11 & & 10 & 2 & \\
\hline $10 \mathrm{II}+5 \mathrm{I}$ & & & & & & & 7 & 2 & & 24 & & \\
\hline $9 \mathrm{II}+7 \mathrm{I}$ & & & & & & & 9 & & & 20 & & \\
\hline $8 I I+9 I$ & & & & & & & 6 & & & 24 & & \\
\hline $7 \mathrm{II}+11 \mathrm{I}$ & & & & & & & 11 & & & 15 & & \\
\hline $6 \mathrm{II}+13 \mathrm{I}$ & & & & & & & 9 & & & 16 & & \\
\hline $5 I I+15 I$ & & & & & & & 10 & & & 11 & & \\
\hline $4 \mathrm{II}+17 \mathrm{I}$ & & & & & & & 8 & & & 6 & & \\
\hline $3 I I+19 I$ & & & & & & & 2 & & & 7 & & \\
\hline $2 \mathrm{II}+21 \mathrm{I}$ & & & & & & & 1 & & & 1 & & \\
\hline $1 \mathrm{II}+23 \mathrm{I}$ & & & & & & & 2 & & & 1 & & \\
\hline $25 \mathrm{I}$ & & & & & & & 1 & & & & & \\
\hline Total & 57 & 40 & 115 & 78 & 48 & 40 & 69 & 86 & 63 & 168 & 87 & 55 \\
\hline
\end{tabular}


long and semi-spreading panicles, wide and long leaves, and semi-sterility.

Type J: Hanging of flag-leaf, awnedness, purple apiculus, drooped, soft and light green leaves, imperfect panicle emergence, late heading, and sterility.

Type K: Awnedness, horizontal stretch of flag-leaf, reduction in height, exserted stigma after flowering, and low fertility.

Type L: Small angle and shortness of flag-leaves, slightly wide and dark green leaves, awnedness, imperfect panicle emergence, slightly late heading, and sterility.

The morphological characteristics such as leaf color, awnedness, leaf width, plant height and leaf drooping found in the alien chromosome addition lines were similar to those described in the trisomics of O. sativa (Hu 1968). But in such characteristics as purple coloration of the apiculus (types I and J), semi-spreading panicle (type $\mathrm{D}$ ), exserted stigma (type $\mathrm{K}$ ) and the occurrence of the same acid phosphatase zymogram as O. officinalis (W0065, type $\mathrm{H}$ ), the alien chromosome addition lines differed from the trisomics.

Cytological observations: The chromosome configurations observed at MI of PMCs of the twelve types of alien chromosome lines (Fig. 2-a) are summarized in Table 4. The twelve types were classified into three groups on the basis of chromosome configurations, i.e., 1) showing 1 trivalent and 11 bivalents with a high frequency (types $\mathrm{A}$ and B, Fig. 2-b), 2) showing a disturbance in the pairing of homologous chromosomes of genome A (types G and J, Fig. 2-d), and 3) having 12 bivalents and 1 univalent (all other types, Fig. 2-c).

The frequencies of trivalents at MI of the types $\mathrm{A}$ and $\mathrm{B}$ were $67 \%$ and $48 \%$,
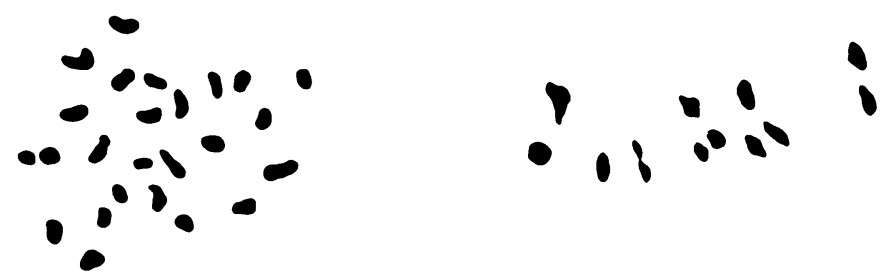

a

b
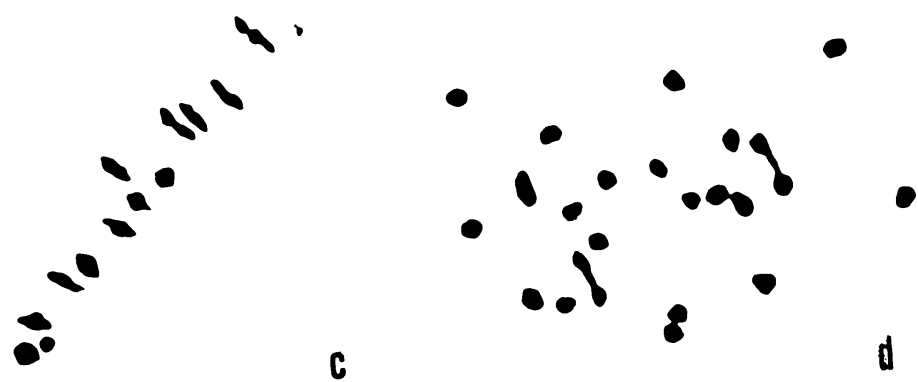

Fig. 2. Somatic chromosomes and chromosome configurations at $\mathrm{MI}$ of alien monosomic addition lines.

a: $2 n=25$. b: $1_{\mathrm{III}}+11_{\mathrm{II}}$ (A type). c: $12_{\mathrm{II}}+1_{\mathrm{I}}$ (C type).

d: 3 II $+19_{\text {I }}$ (G type). 
respectively. The number of trivalents per cell ranged from 0 to 1 with a mean of 0.7 in the type $A$, and 0 to 1 with a mean of 0.5 in the type $B$, as shown in Table 5 . The frequencies of trivalents found in the types $\mathrm{D}, \mathrm{I}, \mathrm{J}$, and $\mathrm{L}$ were $10,11,4$, and 6 percent, respectively.

Table 5. Range and mean of chromosome pairing per PMCs at MI of alien monosomic addition lines

\begin{tabular}{|c|c|c|c|c|c|c|c|}
\hline \multirow{3}{*}{$\begin{array}{l}\text { Plant } \\
\text { type }\end{array}$} & \multirow{3}{*}{$\begin{array}{l}\text { No. of cells } \\
\text { observed }\end{array}$} & \multicolumn{6}{|c|}{ Chromosome pairing at $\mathrm{MI}$} \\
\hline & & \multicolumn{2}{|c|}{$\mathrm{III}$} & \multicolumn{2}{|c|}{ II } & \multicolumn{2}{|c|}{ I } \\
\hline & & Range & (Mean) & Range & (Mean) & Range & (Mean) \\
\hline A & 57 & $0-1$ & $(0.67)$ & $11-12$ & (11.3) & $0-1$ & $(0.3)$ \\
\hline B & 40 & $0-1$ & $(0.48)$ & $11-12$ & (11.5) & $0-3$ & $(0.5)$ \\
\hline $\mathrm{C}$ & 115 & 0 & $(0.00)$ & $11-12$ & $(12.0)$ & $1-3$ & (1.1) \\
\hline $\mathrm{D}$ & 78 & $0-1$ & $(0.10)$ & $11-12$ & (11.9) & $0-3$ & $(1.0)$ \\
\hline $\mathrm{E}$ & 48 & $0-1$ & $(0.02)$ & $11-12$ & $(12.0)$ & $0-3$ & $(1.0)$ \\
\hline $\mathrm{F}$ & 40 & $0-1$ & $(0.03)$ & $11-12$ & $(12.0)$ & $0-1$ & ( 1.0$)$ \\
\hline G & 69 & $0-1$ & $(0.01)$ & $0-12$ & $(6.5)$ & $1-25$ & (11.9) \\
\hline $\mathrm{H}$ & 86 & $0-1$ & $(0.01)$ & $10-12$ & (11.8) & $0-5$ & (1.3) \\
\hline I & 63 & $0-1$ & $(0.11)$ & $11-12$ & $(11.9)$ & $0-1$ & $(0.9)$ \\
\hline $\mathrm{J}$ & 168 & $0-1$ & $(0.13)$ & $1-12$ & $(7.9)$ & $0-23$ & ( 8.9) \\
\hline $\mathrm{K}$ & 87 & 0 & $(0.00)$ & $11-12$ & $(12.0)$ & $1-3$ & $(1.0)$ \\
\hline $\mathrm{L}$ & 55 & $0-1$ & $(0.06)$ & $11-12$ & (11.9) & $0-1$ & $(0.9)$ \\
\hline
\end{tabular}

The chromosome configurations observed in the types $\mathrm{C}, \mathrm{D}, \mathrm{E}, \mathrm{F}, \mathrm{H}, \mathrm{I}, \mathrm{K}$, and $\mathrm{L}$ were $12_{\mathrm{II}}+1_{\mathrm{I}}$ (Tables 4 and 5 ). No difference in the chromosome configurations was observed within these eight types except for occasional trivalent formation.

On the other hand, the number of univalents per cell ranged from 1 to 25 with a mean of 11.9 in the type $\mathrm{G}$, and $\mathrm{O}$ to 23 with a mean of 8.9 in the type $\mathrm{J}$.

\section{DISCUSSION}

To obtain alien chromosome addition lines, allotriploid plants were used as the male parent by some workers (Sears 1956; Thomas 1968; Alston 1970), and as the female parent by others (Riley and Chapman 1958; Evans and Jenkins 1960; Wu et al. 1967). In the present experiment, the authors used the allotriploid plant (AAC) as the female parent and made no castration because they were completely pollen sterile.

The chromosome added to an alien addition line can be specified by three criteria, namely, the morphology of the chromosome, morphological characteristics of the plants, and the meiotic behavior of the chromosomes in the $F_{1}$ plants between two alien chromosome addition lines. Although the karyotype of $O$. officinalis is not clear yet, the $2 n=25$ plants obtained could be classified into 12 groups from their morphological characteristics.

Therefore, it was assumed that each of them had a different additional chromo- 
some introduced from $O$. officinalis and each chromosome had a different effect on phenotypic expression.

$\mathrm{Wu}$ et al. (1967) observed an addition line of $O$. sativa (AAE) having the satchromosome of $O$. australiensis (EE). Ku et al. (1969a) used the technique of paper chromatography for identification of their alien addition lines with $O$. australiensis chromosomes. They concluded that all additional chromosomes except $\mathrm{E}_{7}$ (australian chromosome no. 7) were almost indistinguishable by the chromatographic technique. In the present experiment, the type $\mathrm{H}$ only had the same acid phosphatase zymogram as of O. officinalis (Shin 1977).

As mentioned above six chromosomes of $O$. officinalis carried by the types A, B, $\mathrm{D}, \mathrm{I}, \mathrm{J}$, and $\mathrm{L}$ formed trivalents with their homologous partners of $O$. sativa. This suggests that these six officinalis chromosomes have some homology with sativa chromosomes; the degree of homology between the chromosomes of genomes A (O. sativa) and $\mathrm{C}$ (O. officinalis) may be differently evaluated according to individual chromosome pairs. In the monosomic addition lines, Mochizuki (1962) recognized that six of the seven Agropyron chromosomes had homologous segments with Triticum durum chromosomes.

Based on the stainability and size of chromosomes at MI of PMCs, however, Ku et al. $(1969 \mathrm{~b})$ found no $\mathrm{AAE}$ association in the alien addition lines $\left(\mathrm{AA}+\mathrm{E}_{X}\right)$ of $O$. sativa $\times O$. australiensis, although chromosome pairing was observed more frequently between genomes than within genomes in the $\mathrm{F}_{1}$ plant of $O$. sativa $\times O$. australiensis. From this fact, they considered that the $\mathrm{E}$ chromosomes failed in competition for pairing with its partially homologous A chromosomes.

The asynaptic and desynaptic genes controlling chromosome pairing at MI of PMCs have been reported in Zea (Beadle 1933), Triticum (Li et al. 1945; Riley et al. 1959) and other plants. The asynapsis or desynapsis was in most cases controlled by a single recessive gene.

Though in the present study the pachytene chromosomes were not observed and the genetic control of univalent formation in the types $G$ and $J$ remained unknown, two chromosomes of $O$. officinalis (W0065) may be considered to carry asynaptic or desynaptic genes disturbing the pairing of sativa chromosomes.

In the $F_{1}$ plants of $O$. sativa $\times$ O. officinalis, Shastry et al. (1961) as well as Katayama (1965) observed that the pachytene chromosomes did pair but there were no normal bivalents at MI. They assumed the presence of desynaptic genes controlling this phenomenon. But other workers observed in the same species hybrid that the chromosomes did not pair normally at both pachytene ( $\mathrm{Li}$ et al. 1963) and MI stages (Morinaga et al. 1958; Nezu et al. 1960), and considered that there was no homology of chromosomes between the $\mathrm{A}$ and $\mathrm{C}$ genomes. This discrepancy found in the pairing of pachytene chromosomes among these workers might be due to their use of different strains of $O$. officinalis. 


\section{ACKNOWLEDGMENTS}

The authors wish to express their thanks to Dr. Y. Watanabe, National Institute of Agricultural Sciences at Hiratsuka, Dr. H. I. Oka, National Institute of Genetics at Mishima and Dr. T. Ogawa, Chugoku Agricultural Experiment Station at Fukuyama, for supplying materials used for this experiment.

\section{LITERATURE CITED}

Alston, F.H., 1970 The addition of individual chromosomes of Aegilops squarrosa to Triticum durum. Cytologia 35: 402-408.

Beadle, G. W., 1933 Further studies of asynaptic maize. Cytologia 4: 269-287.

Evans, L.E., and B.C. Jenkins, 1960 Iudividual Secale cereale chromosome additions to Triticum aestivum. 1. The addition of individual "Dakold" fall rye chromosomes to "Kharkov" winter wheat and their subsequent identification. Can. J. Genet. Cytol. 2: 205-215.

Hu, C.H., 1968 Studies on the development of twelve types of trisomics in rice with reference to genetic study and breeding program. J. Agri. Assoc. China 63: 53-71 (in Chinese with English summary).

Katayama, T., 1965 Cytogenetical studies on the genus Oryza. 1. Chromosome pairing of interspecific hybrid $O$. sativa $\times O$. officinalis under different temperature conditions. Japan. J. Genetics 40: 307-313.

Katayama, T., and J.L. Chern, 1973 Zymographic studies on diploid Oryza punctata and its related species. Japan. J. Breed. 23: 329-333.

$\mathrm{Ku}, \mathrm{Y} ., \mathrm{L} . \mathrm{Wu}$, and H.W. $\mathrm{Li}, 1969$ a The phenolic compound differentiation between the cross of Oryza sativa (AA) and O. australiensis (EE). Bot. Bull. Acad. Sinika 10:36-41.

$\mathrm{Ku}, \mathrm{Y} ., \mathrm{C} . \mathrm{H}$. Yuan, and H.W. Li, $1969 \mathrm{~b}$ Specific or random pairing in the $\mathrm{F}_{1}$ and simplex plants $\left(\mathrm{AA}+\mathrm{E}_{\mathrm{X}}\right)$ of Oryza sativa $\times O$. australiensis. Bot. Bull. Acad. Sinica 10: 47-50.

Li, H. W., C.C. Chan, Katherine C.L. Lu., H. K. Wu, and C. H. Hu, 1963 Pachytene studies of the hybrid Oryza sativa $\times$ O. officinalis. Proc. Symp. Rice Genet. Cytogenet. at IRRI. pp. 141-142. Elsevier Publ. Co., Amsterdam.

Li, H. W., W. K. Pao, and C. H. Li, 1945 Desynapsis in the common wheat. Am. J. Bot. 32:92-101.

Mochizuki, A., 1962 Agropyron addition lines of durum wheat. Seiken Ziho 13: 133-139.

Morinaga, T., H. Kuriyama, and S. Ono, 1958 On the interspecific hybrid of Oryza sativa and O. officinalis. Japan. J. Breed. 8: 189 (Abst. in Japanese).

Mukade, K., M. Kamio, and K. Hosoda, 1970 The transfer of leaf-rust resistance from rye to wheat by intergenetic addition and translocation. Gamma Field Symp. (Japan) 9: 69-86.

Nezu, M., T.C. Katayama, and H. Kihara, 1960 Genetic study of the genus Oryza. 1. Crossability and chromosomal affinity among 17 species. Seiken Ziho 11: 1-11.

Riley, R., and V. Chapman, 1958 The production and phenotypes of wheat-rye chromosome addition lines. Heredity 12:301-315.

Riley, R., V. Chapman, and G. Kimber, 1959 Genetic control of chromosome pairing in intergenetic hybrids with wheat. Nature 183: 1244-1246.

Sears, E. R., 1956 The transfer of leaf-rust resistance from Aegilops umbellulata to wheat. Brookhaven Symposia on Biology 9: 1-22.

Shastry, S.V.S., S. D. Sharma, and D.R. Ranga Rao, 1961 Pachytene analysis in Oryza. III. Meiosis in an inter-sectional hybrid, $O$. sativa $\times O$. officinalis. The Nucleus 4: 67-80.

Shin, Y. B., 1977 Morphological and cytogenetical studies on alien additional lines of $O$. sativa with single chromosome of $O$. officinalis. Dr. Thesis, Kyushu University, Japan (in Japanese).

Shin, Y.B., T. Ogawa, and T. Katayama, 1978 Cytogenetical studies on the genus Oryza. VIII. 
Cytogenetics on the allotriploids, sativa $(4 \mathrm{x})$-punctata, sativa $(4 \mathrm{x})$-intermediate form and sativa $(4 \mathrm{x})$-officinalis. Japan. J. Breed. 28: 56-62.

Thomas, H., 1968 The addition of single chromosomes of Avena hirtula to the cultivated hexaploid oat A. sativa. Can. J. Genet. Cytol. 10: 551-563.

Wu, L., K.S. Tsai, and H.W. Li, 1967 Cytogenetical studies of Oryza sativa L. and its related species. 12. An alien additional line second backcross generation of $O$. sativa $\times$ O. australiensis. Bot. Bull. Acad. Sinica 8: 165-170. 